\title{
Relationship Risk Analysis in Project Governance
}

\author{
Xing-Zhi LIU ${ }^{1, a}$, Rong-Kun LIU,
}

${ }^{1}$ School of Business Administration, Shandong University of Finance and Economics,No.7366, Erhuan Dong Road, Jinan City, Shandong province, P.R. China 250014

\author{
${ }^{2}$ Shandong Normal University, Business School, Lecturer,Room 500, Yi Fu Building, Shandong \\ Normal University,No.88, Wenhua Dong Road, Jinan City, Shandong province, P.R. China 250014 \\ aq_100@163.com, Irk8284@126.com \\ ${ }^{*}$ Corresponding author
}

Keywords: Social network analysis, Project governance, Stakeholder, Relationship risk.

\begin{abstract}
Project governance theory is increasingly wide attention of theoretical and practical circles. The research emphasize the governance relationships between project stakeholders is critical to the success of the project, the relationship risk control as the core of project governance. However, existing research does not form the general theory and methods of relationship risk analysis that can be applied to different projects with different characteristics, and also did not put forward a unified strategy choice theory and method on how to reduce risk. Seeking a new theory and method to analysis and disposal project stakeholders' relationship risk is of great significance. This article uses Social Network Analysis method constructs whole project stakeholders' relationship risk analysis process, which contains: the construction of project governance network model, the measurement of relationship risk and the selection of strategy.
\end{abstract}

\section{Introduction}

In the process of China's rapid economic growth, all kinds of projects, especially large projects across the organization constantly emerging, various types of problems, such as project investment out of control, quality accident, project delay, happen occasionally[1]. The traditional single project management which with project manager as the core as well as theory and methods of programme management and portfolio management which with a single organization as the boundary have gradually shown its shortcomings[2]. Standishgroup survey results show that the important cause leading to the project failure is the failure of governance relationship between project stakeholders[3]. The project governance theory, which core tasks include how to determine the project goals, select the project implementation strategy, establish information disclosure and monitoring mechanisms ,is increasingly wide attention of theoretical and practical circles.

Project governance research began in the late $1990 \mathrm{~s}$, mainly based on three research perspectives: the perspective of corporate governance, governance structure and process character perspective. First two perspectives are transplanting the Corporate Governance Theory, Principal-Agent Theory, Stakeholder Theory, and Beyond Property-Right Argument into project management, trying to achieve the balance of responsibility, right and benefit between project stakeholders, form an effective risk and benefit sharing mechanism, prompt stakeholders' action coordinately for the success of project[4]; Project governance theory based on process role perspective believes that project governance is the process of establishing and maintaining the relationship between project stakeholders, this process will create a good environment for the project management, so as to reduce project risk, improve project success rate[2]. Although three different research perspectives, but essentially stressed that stable and reliable relationship between project stakeholders is critical to the success of the project governance.

However, existing research does not form the general theory and methods of relationship risk analysis that can be applied to different projects with different characteristics, and also did not put forward a unified strategy choice theory and method on how to reduce risk. Current studies of 
project risk management, mainly focus on the analysis and research on associated risk factors with a single stakeholder role behavior, or only consider relationship risk between two stakeholders,[5][6]called binary "relationship" in this study. These studies neglected the network relationship between many stakeholders, and therefore does not reflect and solve the core issue of project governance. So, seeking a new theory and method to analysis and disposal project stakeholders' relationship risk is of great significance.

\section{Literature review}

\section{Research status and trends of project governance relationship.}

The carrier of project task is temporary organization consisting of multiple stakeholders, between these stakeholders, different project governance relationship are formed around the agreement on the project objectives, project implementation strategy, and the disclosure and monitoring of information in the process of project implementation. The study of governance relationship can be divided into two categories, "binary" relationship and network relationship.

\section{The research of "binary" relationship.}

This type of research believes that "binary" relationship is the basic unit of project governance relationship, and project governance relationship is the simple superposition of "binary" relationship, is divided into the following three aspects: principal-agent relationship [4][7-9], trading relationship[10] and collaborative working relationship[2].

\section{The research of "network" relationship.}

This kind of research believes that the standpoint of seeing project governance relationship as a simple combination of "binary" relationships split the systematicness of project governance. The most representative research results seen project governance relationship as a social network, such as Aaltonen [11],Pryke and Pearson[12], Masquefa [13] , Ferriani [14]. These studies also limited in simple network, but provides a good approach for this study.

\section{Research status and trends of project governance risk.}

Governance risk research originated in the corporate governance research field; the term corporate governance risk has been mentioned in Yin-Hua Yeh's research which analyzed the relation between corporate governance and financial crisis, Taiwan's listed companies as samples[15]. Although there is currently no scholars clearly put forward the definition of project governance risk, the related studies have been carried out. Such as research on large construction project risk[6], the risk of BOT project[5], the stability of the supply chain between upstream and downstream relationship[16-19], etc.

Through the analysis of related research on project governance relationship and project governance risk, we found that: First, the study of project stakeholders' relationship focused mostly on binary relationship, but less on network relationship. Second, pay more attention to project "attributes" risk factor analysis, rarely involved the study of stakeholder relationship risk.

\section{The construction of project governance network model}

\section{Network node selection.}

Project governance node is project stakeholder, two key problems need to be solved on identification of project stakeholders: one is to find the project have what stakeholders; the second is the expression of the relationship between the stakeholders. Both aspects contact closely, this research does not intend to discuss respectively from two aspects, but treat the identification of project stakeholder as an whole process, and express it with snowball's thoughts.

Step1: Select a representative stakeholder to get the data. 
A project may involve many stakeholders, identify all stakeholders at a draught is unrealistic. Feasible way is to choose a representative stakeholder to get the data, know about associated stakeholders and their relationship strength. This paper use $S_{i j}^{i}$ represents the relationship strength, superscript represents data source, and the subscript represents edge. Suppose we know about three stakeholders from stakeholder 1, and draw the network diagram as shown in figure 1-(a), the gray node says the stakeholder has been access or investigated, dashed line indicates the connection there is only data from one side, and need to get the data to confirm or correct from other side.

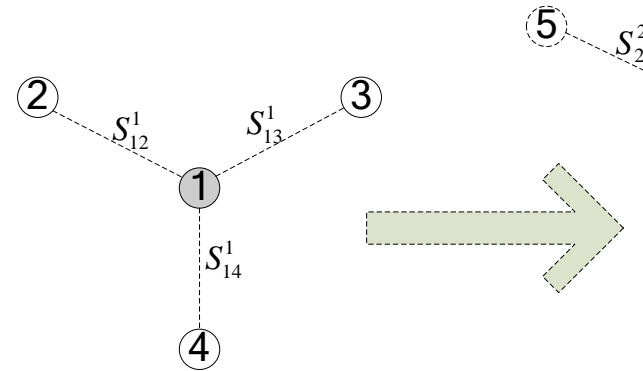

(a)

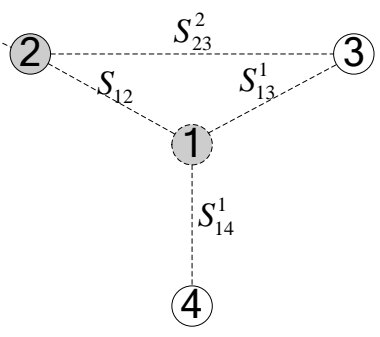

(b)

Fig.1: Drawing process of project governance network diagram

Step2: Select an uninvestigated stakeholder to get the data.

Assumes that the stakeholder 2 is selected, so data $S_{12}^{2}$ can confirm or correct data $S_{12}^{1}$, and we can calculate new data $S_{12}$ according to the formula $S_{i j}=\left\lceil\left(S_{i j}^{i}+S_{i j}^{j}\right) / 2\right\rceil$.

According to the information, draw the network diagram as shown in figure 1-(b), contrast to figure 1-(a), you can found that node 2 by the white background became a gray background, connection between node 1 and 2 by a dotted line becomes a solid line.

Step3: Repeat step 2 until all nodes in the graph is grey background, all connection into a solid line.

\section{Network edge empowerment.}

Project governance network edge represents the project governance relationship between stakeholders; this part will be discussed through the relationship strength measurement for empowerment of project governance network edge.

After getting the initial measurement index through literature analysis, making project interview for many times and expert assessment, ultimately determines the 16 measurement indexes, as shown in table 1.

We can get original data by questionnaire. The five-level magnitude scale method is adopted in this study, that is, \{higher, high, medium, low, lower $\}$, the corresponding score is, $\{5,4,3,2,1\}$, used to express the degree of the problem description conforming to the actual situation.

When calculating the primary index score, firstly, calculate the geometric mean of secondary indexes, and then calculate the weighted average of primary indexes to get the value of relationship strength S. Computation formula is:

$$
\mathrm{S}=\left[\begin{array}{l}
W_{X R} \times \sqrt[4]{X R_{1} \bullet X R_{2} \bullet X R_{3} \bullet X R_{4}} \\
+W_{C N} \times \sqrt[6]{C N_{1} \bullet C N_{2} \bullet C N_{3} \bullet C N_{4} \bullet C N_{5} \bullet C N_{6}} \\
+W_{H Z} \times \sqrt{H Z_{1} \bullet H Z_{2}} \\
+W_{J C} \times \sqrt[4]{J C_{1} \bullet J C_{2} \bullet J C_{3} \bullet J C_{4}}
\end{array}\right]
$$


Thereinto, the weight of each dimension was calculated by using the software of Super Decisions, and the judgment matrix was got from nine project management experts, the result was:

$$
\left(W_{X R} \quad W_{C N} \quad W_{H Z} \quad W_{J Z}\right)^{T}=(0.357756,0.330836,0.225711,0.085697)^{T}
$$

Tab.1 Stakeholder relationship strength measurement indexes

\begin{tabular}{|c|c|c|c|}
\hline \multirow{17}{*}{$\begin{array}{l}\text { Relationship } \\
\text { strength }\end{array}$} & dimension & index & $\begin{array}{l}\text { Description } \\
\end{array}$ \\
\hline & \multirow{4}{*}{ Trust } & $\mathrm{XR}_{1}$ & $\begin{array}{l}\text { We believe that the partner has the ability to complete the project } \\
\text { tasks on time and ensure the quality. }\end{array}$ \\
\hline & & $\mathrm{XR}_{2}$ & $\begin{array}{l}\text { We believe that the partner will fully consider our interest in } \\
\text { making important decisions. }\end{array}$ \\
\hline & & $\mathrm{XR}_{3}$ & We believe that the partner will help us when we need. \\
\hline & & $\mathrm{XR}_{4}$ & We believe that the partner will live up to its promise. \\
\hline & \multirow{6}{*}{$\begin{array}{l}\text { Relationship } \\
\text { commitment }\end{array}$} & $\mathrm{CN}_{1}$ & $\begin{array}{l}\text { Terminate the relationship with each other will bring us heavy } \\
\text { losses. }\end{array}$ \\
\hline & & $\mathrm{CN}_{2}$ & $\begin{array}{l}\text { Terminate the relationship with each other will bring significant } \\
\text { loss to project. }\end{array}$ \\
\hline & & $\mathrm{CN}_{3}$ & We have a strong sense of loyalty to the partner. \\
\hline & & $\mathrm{CN}_{4}$ & We have a very close relationship with the partner. \\
\hline & & $\mathrm{CN}_{5}$ & We are very pleasure to cooperate with the partner. \\
\hline & & $\mathrm{CN}_{6}$ & $\begin{array}{l}\text { We are willing to do our best to devote resources to maintain the } \\
\text { relationship with the partner. }\end{array}$ \\
\hline & \multirow{2}{*}{ Cooperative } & $\mathrm{HZ}_{1}$ & We have strong task dependencies with the partner. \\
\hline & & $\mathrm{HZ}_{2}$ & We have strong resource dependence relationship with the partner. \\
\hline & \multirow{4}{*}{$\begin{array}{l}\text { Contact } \\
\text { time }\end{array}$} & $\mathrm{JC}_{1}$ & We have frequent formal communication with the partner. \\
\hline & & $\mathrm{JC}_{2}$ & We have frequent informal communication with the partner. \\
\hline & & $\mathrm{JC}_{3}$ & We have years of formal communication with the partner. \\
\hline & & $\mathrm{JC}_{4}$ & We have years of informal communication with the partner. \\
\hline
\end{tabular}

\section{Stakeholder relationship risk analysis}

\section{The definition of relationship risk.}

Stakeholders participate in the project is actually a kind of investment behavior, its fundamental purpose is to achieve a certain return on investment.

Project stakeholders have their own interests, and have the power to choose their own behavior. Therefore, among stakeholders in project governance, there is still a certain competition in pursuit of yield, efforts for the realization of the expected yields. Each stakeholder has a network structure consisting of its own and its related parties in this competitive field. Something in the network structure, as well as the stakeholders' position in the social network made him in a competition or risk state; determine the return on his investment. In conclusion, the project stakeholders' position in the project governance social network has important influence to the realization of the expected yields; this article defines the influence as the relationship risk.

\section{The measurement of relationship risk.}

What countermeasure would be taken in project governance for a certain stakeholder depends on two aspects: one is the stakeholders' status and rights in the network, this study called the influence; the second is the restriction from other stakeholders in the network. When we look at the relationship risk for a certain stakeholder in the project governance social network, we called the certain stakeholder as Focal Stakeholder.

\section{Influence measurement method design}

In the literature of social network, three kinds of centrality most discussed are Degree, Closeness and Betweenness, them reflects the central state of Focal Stakeholders in the network from different 
sides. Brass and Burkhardt (1993) clearly points out the difference between them, that Degree focus measure the direct relationships between Focal Stakeholder and other stakeholders, Closeness for expressing the distance from Focal Stakeholder to all the other stakeholders, Betweenness for expressing Focal Stakeholder's ability to control other stakeholders. By comparing three kinds of centrality can reach centrality design principles: First, the need to consider not only direct relationship, also need to consider the indirect relationship; Second, not only to consider the shortcut, but also consider other paths.

Based on the above two guiding principles, considering the features of project governance network, we design a new suitable centrality calculation method-Flow Centrality $\mathrm{C}_{\mathrm{F}}$, used to measure the influence of Focal Stakeholder in project governance social network.

$$
C_{F}\left(n_{i}\right)=\sum_{j<k} F_{j k}\left(n_{i}\right)=\sum_{j<k} F_{j k} \times f_{j k}\left(n_{i}\right)
$$

Thereinto, $F_{j k}$ is the maximum information flow between node $n_{j}$ and node $n_{k}, F_{j k}\left(n_{i}\right)$ is the information flow through node $n_{i}$ in $F_{j k}, f_{j k}\left(n_{i}\right)$ is the proportion of $F_{j k}\left(n_{i}\right)$ in $F_{j k}$.

\section{Restriction measurement method design}

For Focal Stakeholder, the size of restriction is related to the density of Ego-network. The higher the density of Ego-network, the greater the communication efficiency. The spread of the various standards will lead to form visible and common expectations between project participants, to make network participants to have consistent behavior. It is difficult to form a negotiating advantage in the face of the high density Ego-network for Focal Stakeholder. So, the higher the density of Ego-network, the greater the Focal Stakeholder is limited by other stakeholders.

Conversely, in low density or sparse project governance social network, there are less coordination activities between the participants, it is difficult to form the team consciousness, the possibility of forming joint and a unified strategy between project participants is extremely limited. Of course the sparse nature also won't give strong support to against Focal Stakeholder. As a result, the lower the density of Ego-network, the easier to form a negotiating advantage for Focal Stakeholder through the contradiction between network participants.

Network cohesion, network integration and network distance are derived of the concept of network density; they are can express the restriction faced by Focal Stakeholder in Ego-network on a certain extent. In contrast, network density is more intuitive, simple, this study chooses the network density measure the restriction faced by Focal Stakeholder.

Risk strategy. The relationship risk status faced by Focal Stakeholder can be classified from two dimensions of influence and restriction. Focal Stakeholder will adopt different strategies to cope with different risk condition.

High density-high centrality. In high density Ego-network, other stakeholders have strong restrictions on Focal Stakeholder; however, high centrality gives Focal Stakeholder the ability of resisting other stakeholders. Therefore, Focal Stakeholder and other stakeholders' mutual influence are stronger, and both sides have no ability to control the whole situation, and make the network have a high degree of uncertainty. According to the system dependency theory and resource dependence theory, "organizational decision makers prefer certainty, stability and predictability"[20]. Therefore, when "high density-high centrality" network environment, Focal Stakeholder will take measures to reduce network density in order to increase their comparative advantage, namely the disintegration of the other union; if it is invalid, Focal Stakeholder need to compromise strategy to negotiate with other stakeholders.

Low density-high centrality. Under "low density-high centrality" network condition, Focal Stakeholder has absolute advantage. Low-density network is not conducive to the spread of 
information, does not favor the formation of unified target. Mintzberg, points out that when the other stakeholders could not form resultant force in response to Focal Stakeholder, they will be in a passive position[21]. Instead, the Focal Stakeholder is in the center of the Eco-network with a high centrality, controls the resources, information, and has strong influence. Under such network condition, the Focal Stakeholder is of great freedom, often plays a commander role. At the same time, the Focal Stakeholder should also take corresponding strategy, keep other stakeholders are independent of each other.

High density-low centrality. In this environment, Focal Stakeholder is in a disadvantage position. On one hand, other stakeholders rely on frequent contact, the height of the connection, easy to form a unified goal, consistent action, resulting in a powerful force; on the other hand, Focal Stakeholder is lack of ability to control resources, information. At a disadvantage does not mean that only "passive", Focal Stakeholder need to take effective strategy to improve their positions.

Ally. In social network, actor tends to establish joint relationship with key stakeholder, which is beneficial to the exercise of the privilege[22]. One cooperation method is searching dominant position stakeholder, forming a strategic alliance or merger, as shown in Figure 2.

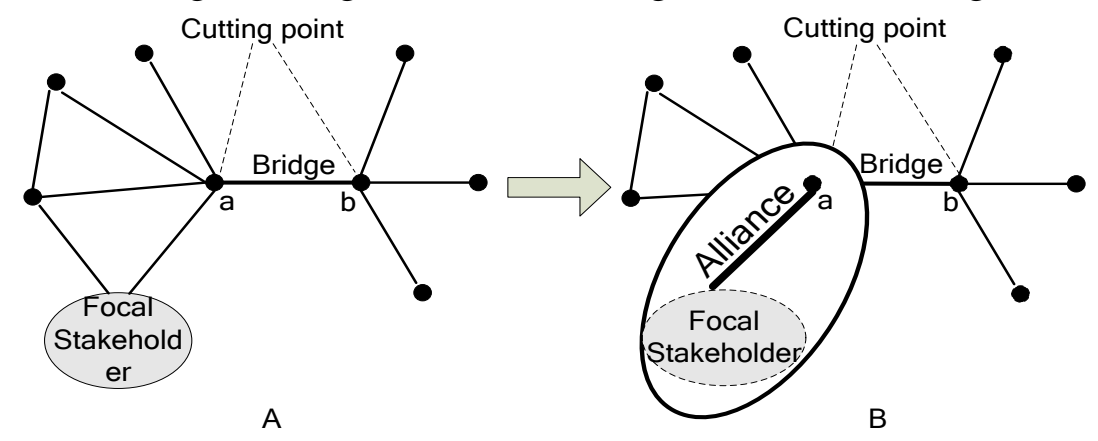

Fig.2: Schematic of alliance strategy

Occupy bridge or cutting point. If two stakeholders have related only via a unique relationship, has described this relationship as bridge. Cutting point is some individuals in the whole network, they play an important mediation role in the network, if they are removed, and then the whole network can be divided to two or more subnet. Bridge or cutting point usually is the key pathway or key point for resource or information exchange. Occupy the position of bridge or cutting point is effective means to consolidate and develop stakeholders' position advantage. Figure 3 illustrates the implementation of the strategy.

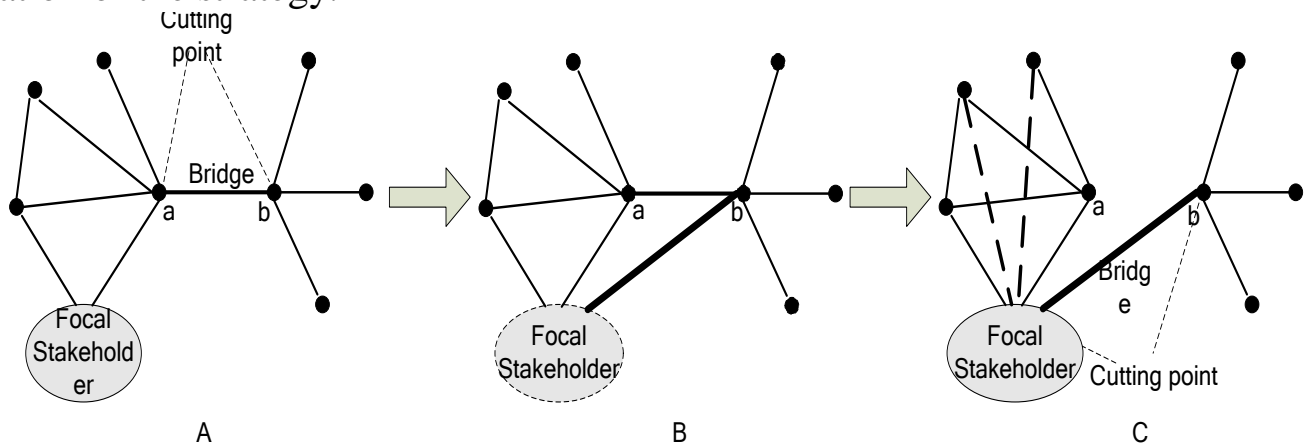

Fig.3: Schematic of occupy bridge or cutting point

Low density-low centrality. Under "low density-low centrality" network condition, the pressure come from other stakeholders is small. At the same time, the Focal Stakeholder is lack of ability to control resources and information. Due to lack of information communication, and monitoring, the Focal Stakeholders' behavior often cannot attract the attention of other stakeholders. As a result, the Focal Stakeholder is often in a state of isolation. However, this situation provides Focal Stakeholder 
a comfortable environment to improve their position, establishing contact with all parties to improve their ability to control resources and information is an optimal choice.

\section{Summary}

Project governance structure view from network perspective reflects characteristics of interactive, initiative, establishes the connection of individual behavior and governance structure, is a kind of interactive process which build bridges between individual seeking rational choice and network restriction. Project stakeholder relationship risk is the core of project governance research. This paper launches the research of project governance relationship risk using Social Network Analysis method, found that: Project governance social network can effectively express the governance relationship between project stakeholders. The project governance relationship risk analysis method constructed from two aspects of influence and restriction can analyze stakeholders' relationship risk effectively and put forward coping strategies.

The Project governance theory research is still very short history; many problems have yet to be further in-depth study. In particular, has the following several aspects:

First of all, the risks to the project stakeholders can be divided into property risk and relationship risk, two aspects complement each other and have close relations, work together with project stakeholders control strategy choice. research covered two aspects has important theory value and practical significance.

Second, the project management dynamic social network, one of the most obvious features is the stage; project stakeholders enter or exit the network as projects from one phase to another phase. How to effectively analyze the inheritance of network relationship and the reconstruction of the network is an issue worth exploring.

Third, the various stakeholders involved in the same project at the same time also involved in other projects, that is to say there is more than one project governance social network related. It is more systemic to extend study range from a single project to multiple projects.

\section{Acknowledgements}

This work was financially supported by the Program for Shandong Provincial Soft Science Research and Planning (2013RKB01441), Research Award Fund for Outstanding Young Scientist in Shandong Province (BS2012SF028), Natural Science Fund for Youth in Shandong Province (ZE2010GQ004), Ministry of Education of Humanities and Social Science Youth Fund (11YJCZH088), Shandong University of Finance and Economics Doctor Fund (B13017).

\section{References}

[1] Liguo W, Ya J, Xin Y. Construction Mode Innovation of Our Public Project: Probing into Third-party Supervision Model[J]. Academic Exchange. 2012(1): 96-99.

[2] Rong-Gui D, Zu-Ye Z, Xing-Zhi L. Key Problems in the Governance of Science and Technology Projects Invested by Government and Their Solution[J]. China Soft Science. 2012(1): 90-99.

[3] Self R J, Aquilina C. TechnoStress in the 21st Century; Does It Still Exist and How Does It Affect Knowledge Management and Other Information Systems Initiatives[C]. Springer, 2013.

[4] Gu Q, Yang W, Dai D. Review of Theoretical Study and Progress on Project Governance Theory[J]. Construction Economy. 2012(2): 64-67.

[5] Wang S Q, Tiong L K. Case study of government initiatives for PRC's BOT power plant project[J]. International Journal of Project Management. 2000, 18(1): 69-78. 
[6] Lee E, Park Y, Shin J G. Large engineering project risk management using a Bayesian belief network[J]. Expert Systems with Applications. 2009, 36(3, Part 2): 5880-5887.

[7] Turner J R, Keegan A. Mechanisms of governance in the project-based organization:: Roles of the broker and steward[J]. European Management Journal. 2001, 19(3): 254-267.

[8] Turner J R, Müller R. Communication and Co-operation on Projects Between the Project Owner As Principal and the Project Manager as Agent[J]. European Management Journal. 2004, 22(3): 327-336.

[9] Turner J R. Towards a theory of project management: The nature of the project governance and project management[J]. International Journal of Project Management. 2006, 24(2): 93-95.

[10] Winch G M. Governing the project process: a conceptual framework[J]. Construction Management \& Economics. 2001, 19(8): 799-808.

[11] Aaltonen K, Kujala J, Lehtonen P, et al. A stakeholder network perspective on unexpected events and their management in international projects[J]. International Journal of Managing Projects in Business. 2010, 3(4): 564-588.

[12] Pryke S, Pearson S. Project governance: case studies on financial incentives[J]. Building Research \& Information. 2006, 34(6): 534-545.

[13] Masquefa B. Top management adoption of a locally driven performance measurement and evaluation system: A social network perspective[J]. Management Accounting Research. 2008, 19(2): 182-207.

[14] Ferriani S, Cattani G, Baden-Fuller C. The relational antecedents of project-entrepreneurship: Network centrality, team composition and project performance[J]. Research Policy. 2009, 38(10): 1545-1558.

[15] Lee T, Yeh Y. Corporate Governance and Financial Distress: evidence from Taiwan[J]. Corporate Governance: An International Review. 2004, 12(3): 378-388.

[16] Loosemore M, Mccarthy C S. Perceptions of contractual risk allocation in construction supply chains[J]. Journal of Professional Issues in Engineering Education and Practice. 2008, 134(1): 95-105.

[17] Sodhi M S, Son B G, Tang C S. Researchers' perspectives on supply chain risk management[J]. Production and Operations Management. 2012, 21(1): 1-13.

[18] Trkman P, Mccormack K. Supply chain risk in turbulent environments-A conceptual model for managing supply chain network risk[J]. International Journal of Production Economics. 2009, 119(2): 247-258.

[19] Yang J, Wang J, Wong C W, et al. Relational stability and alliance performance in supply chain[J]. Omega. 2008, 36(4): 600-608.

[20] Oliver C. Strategic responses to institutional processes[J]. Academy of management review. 1991, 16(1): 145-179.

[21] Mintzberg H. Power in and around organizations[M]. Englewood Cliffs, NJ: Prentice-Hall, 1983.

[22] Chinyio E, Olomolaiye P. Construction stakeholder management[M]. Wiley Online Library, 2009. 